Faculdade de Ciências Econômicas UFRGS
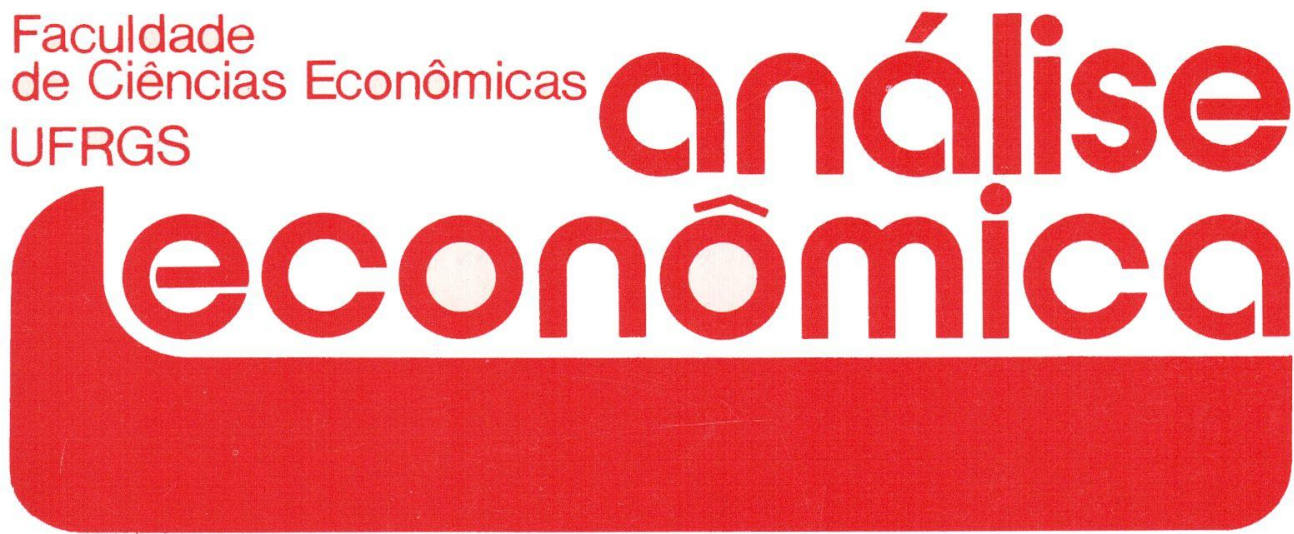

- STATE AND THE LIBERALIZATION OF THE BRAZILIAN ECONOMY

Carlos Alberto Longo

- MOEDA E CRÉDITO NA ECONOMIA BRASILEIRA: UM MODELO COM VETORES DE CORREÇÃO DE ERROS

Rolando M. Guzmán

- baSES PARA UM NOVO MOdELO DE POLítica FISCAL, PARA O BRASIL

Flávio Riani

- POR QUE OS SINOS DOBRAM? CONFLITO TRABALHISTA E SALÁRIOS DO MAGISTÉRIO PÚBLICO DO RIO GRANDE DO SUL, 1974-1991

Carlos Henrique Horn

Roberto Balau Calazans

- A POLÍtica MONETÁRIa E AS TAXAS de JUROS NO PLANO COLLOR

Lauro Lobo Burle

- DIFUSÃo E TRANSFERÊNCIA DA TECNOLOGIA DE PRODUÇÃO DE CIMENTO NO BRASIL

Maria Cristina Pereira de Melo

- SISTEMA FINANCEIRO BRASILEIRO: UMA PROPOSTA dE disCuSSÃo

Luiz Felipe Serpa

- TEORIA ECONÓMICA DO CASAMENTO E DO Divórcio

Giácomo Balbinotto Neto

- RESENHA

VARGAS: O CAPITALISMO EM CONSTRUÇÃO, DE PEDRO C. D. FONSECA

João Rogério Sanson

- LIVROS RECEBIDOS

Claudine Saldanha César
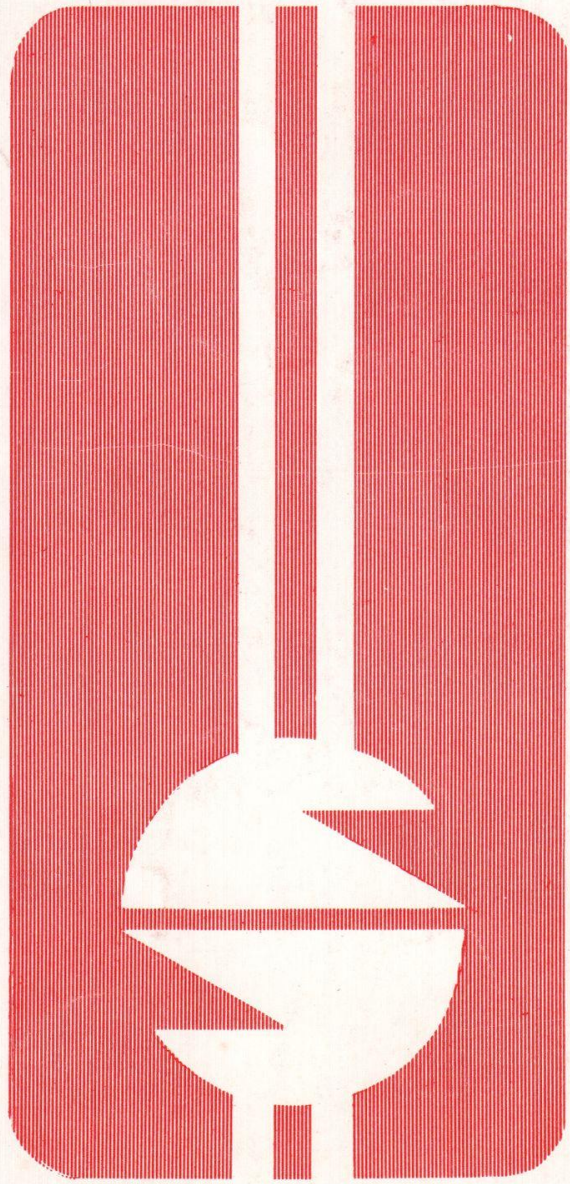
UNIVERSIDADE FEDERAL DO RIO GRANDE DO SUL

Reitor: Prof. Hélgio Henrique Casses Trindade

FACULDADE DE CIÉNCIAS ECONÔMICAS

Diretora: Prof ${ }^{a}$ Yeda Rorato Crusius

CENTRO DE ESTUDOS E PESQUISAS ECONÔMICAS

Diretor: Reinaldo Ignacio Adams

DEPARTAMENTO DE CIENNCIAS ECONÔMICAS

Chefe: Prof. Fernando Ferrari Filho

CURSO DE PÓS-GRADUAÇÃO EM ECONOMIA

Coordenador: Prof. João Rogério Sanson

CURSO DE PÓS-GRADUAÇÃO EM ECONOMIA RURAL

Coordenador: Prof. Juvir Luiz Mattuella

CONSELHO EDITORIAL: Achyles Barcelos da Costa, Aray Miguel Feldens, Atos Freitas Grawunder, Carlos Augusto Crusius, ErnaniHickmann, Fernando Ferrari Filho, João Rogério Sanson, Juvir Luiz Mattuella, Maria Imilda da Costa e Silva, Nali de Jesus de Souza, Nuno Renan Lopes de Figueiredo Pinto, Otília Beatriz Kroeĩ Carrion, Otto Guilherme Konzen, Paulo Alexaridre Spohr, Pedro Cezar Dutra Fonseca, Reinaldo Ignacio Adams, RobertsCamps Moraes, Valter José Stülp, Yeda Rorato Crusius, David Garlow (Wharton Econometrics Forecasts Association, E.U.A.), Edgar Augusto Lanzer (UFSC), Eleutério F. S. Prado (USP), Fernando Holanda Barbosa (FGV/RJ), Gustavo Franco (PUC/RJ), Joaquim Pinto de Andrade (UiNB), Juan H. Moldau (USP), Werner Baer (Univ. de Illinois, E.U.A.)

COMISSÃO EDITORIAL: Atos Freitas Grawunder, Reinaldo Ignacio Adams, Pedro Cezar Dutra Fonseca, Roberto Camps Moraes.

EDITOR: Nali Jesus de Souza

SECRETARIA: Maria Ivone de Mello (normalização), Vanete Ricacheski (revisão de textos)

FUNDADOR: Prof. Antônio Carlos Santos Rosa

Os materiais publicados na Revista Análise Econômica são de exclusiva responsabilidade dos autores. É permitida a reprodução total ou parcial dos trabalhos, desde que seja citada a fonte.

Aceita-se permuta com revistas congêneres. Aceitam-se, também, livros para divulgação, elaboração de resenhas ou recensões.

Toda correspondência, material para publicação (vide normas na $3^{a}$ capa), assinaturas e permutas devem ser dirigidos ao seguinte destinatário:

PROF. NALI DE JESUS DE SOUZA

Revista Análise Econômica

Av. João Pessoa, 52

90040-000 - PORTO ALEGRE (RS), BRASIL

Telefones: (051) 228.1633 - 224.6022 - Ramais 3348 ou 3440

FAX: (051) 225.1067 


\section{VARGAS: \\ O CAPITALISMO EM CONSTRUÇÃO}

João Rogério Sanson*

FONSECA Pedro C. D. Vargas: O Capitalismo em Construção. São Paulo: Brasiliense, 1989. 485p.

Vargas: $O$ Capitalismo em Construção é um livro sobre a formação econômica do Brasil. Tem como fio condutor os discursos de Getúlio Vargas, relevantes do ponto de vista de política econômica. O primeiro deles é de 1906, em que o ex-estudante de Humanidades em Ouro Preto (MG) e da escola militar de Rio Pardo (RS), mas agora estudante de Direito em Porto Alegre, participa de uma homenagem ao presidente da República. Já nesse discurso há uma passagem que mostra uma preocupação em proteger a indústria nacional, ao falar sobre quem é coagido a “... comprar, manufaturados do estrangeiro, os gêneros da própria matéria-prima que exporta" (p.35).

$O$ destaque de Vargas como orador de turma na homenagem presidencial de 1906 não deve surpreender, por maiores que fossem os seus dons de oratória. Suas ligações familiares com os nolíticos que comandavam o Estado certamente estavam por trás dessa chance de falar em evento tão importaiite. Também deviam estar por trás do discurso de três anos antes, em sessão fúnebre no Teatro São Pedro para Júlio de Castilhos, o positivista que escreveu a constituição gaúcha e que comandava a política no Estado. O pai de Getúlio, embora um chefe político no interior, era membro destacado do Partido Republicano Riograndense. Então com vinte anos de idade, Getúlio estava no primeiro ano da faculdade.

* Professor do Curso de Pós-Graduação em Economia da UFRGS

\begin{tabular}{|l|l|l|l|l|}
\hline ANÁLISE ECONÔMICA & ANO 10 & N:18 & SETEMBRO/92 & P. 143-145 \\
\hline
\end{tabular}


O último documento analisado por Fonseca é a carta-testamento, divulgada no dia do suicídio de Vargas, em 1954. As circunstâncias em que a carta foi escrita são relacionadas à crise da fase populista de Vargas.

De acordo com o Cap.l, o ponto de vista teórico é o mesmo de Florestan Fernandes. Dentro da concepção de revolução burguesa desse autor, não teria havido uma ruptura, mas sim uma transformação gradual da economia brasileira. Assim, o período que vai da República Velha ao final do segundo governo de Vargas é visto por Fonseca como "... um momento de introdução, expansão e consolidação do capitalismo, ou seja, de efetivação do poder burguês"(p.26).

Essa interpretação da história brasileira pode ser vista como uma variante da teoria do capitalismo monopolista de Estado. Segundo esta teoria, as economias capitalistas passam por fases: a competitiva, a monopolista e a monopolista de Estado. Na verdade, a Escola Francesa interpreta o capitalismo monopolista de Estado como uma subfase da fase imperialista. Na adaptação para um país periférico, o Estado, com suas ações condicionadas pelas necessidades internas de acumulação, é também influenciado, em diferentes graus, pelo processo de acumulação internacional.

Embora haja essa referência a Florestan Fernandes, Fonseca chama atenção ao fato de que o estudo dos discursos de Vargas é um estudo de ideologias (p.2123). 0 discurso é visto como uma "manifestação da ideuiogia." Inicialmente, a ideologia é positivista, em sua versão castilhista, passando nos anos trinta para algo que podemos descrever como desenvolvimentismo estatista e finalmente tornando-se populista. Antônio Gramsci é citado para enfatizar a importância de se estudar a ideologia e, portanto, a sua expressão na forma dos discursos. Porém a moderna teoria gramsciana do discurso é pouco aproveitada.

Entre as explicações marxistas mais interessantes, como alternativas à do capitalismo monopolista de Estado, estão as teorias baseadas em Gramsci. Elas vão além da idéia básica do "bureau" da burguesia e discutem o surgimento, concorrência (contra-hegemonia) c manutenção de uma ideologia como expressão hegemônica de um grupo sobre a sociedade civil. Embora não independente do processo de acumulação, a ideologia deixa de ser uma mera consequêencia dos modos de produção. Além disso, o simples controle do Estado não ăarante a hegemonia.

Mais especificamente ainda, a abordagem gramsciana do discurso tem-se voltado especialmente para as várias experiências populistas, incluídas aí o fascismo, o nazismo e o caudilhismo latino-americano. Concentra-se no modo como as ideologias são desenvolvidas e usadas na luta pelo poder estatal. Mostra como os elementos ideológicos de caráter nacional-popular podem ser articulados com elementos ideológicos de classes específicas. A busca da hegemonia é feita pela articulação desses diferentes elementos ideológicos (discursos), enfatizando núcleos comuns, mas preservando as características de cada um. No desenvolvimento dessa abordagem, destacam-se Emesto Laclau e Chantal Mouffe. 
Com uma abordagem desse tipo seria possível visualizarouso do liberalismo tanto pelos maragatos (uma das facções da Revolução Federalista de 1893) como pela UDN. O liberalismo seria uma ideologia alternativa para desalojar os castilhistas, no primeiro caso, e o varguismo, no segundo. Fica mais fácil visualizar a permanente busca, por um político profissionalmente competente como Vargas, de meios para manter-se no poder, manobrando entre os múltiplos grupos de interesse da sociedade brasileira. Levaria ao estudo também do papel dos técnicos e políticos diretamente ligados a Vargas durante os seus períodos de poder. Motivaria talvez uma maior atenção, ainda no estudo de Vargas, às explicações da história econômica brasileira baseadas na teoria do patrimonialismo. 0 próprio início da carreira política de Vargas seria uma evidência interessante em favor de tal teoria.

Isto naturalmente ainda deixaria fora a corrente de história econômica que se baseia nas idéias de custos transacionais e num processo evolucionário lamarckiano para explicar o surgimento de instituições viabilizadoras do capitalismo. Quando Getúlio Vargas entrou na vida adulta, a experiência da industrialização apoiada pelo Estado na Alemanha era bem recente e era rátural que grupos passassem a defender uma solução semelhante para o Brasil, num: processo evolucionário de imitação. Aparentemente a literatura brasileira de história econômica ainda não começou a explorar o potencial desse tipo de teoria. Nesse contexto, o trabalho de Fonseca apenas reflete o estado das artes quanto a enfoques teóricos no estudo da nossa história econômica.

Naturalmente é mais fácil sugerir tais alternativas do que realizá-las. 0 trabalho de Fonseca, com o enfoque teórico adotado, representa uma contribuição significativa para a historiografia brasileira.

Cada capítulo cobre uma subfase relevante tanto do desenvolvimento do capitalismo no Brasil como do próprio personagem principal. No cap.2, somos introduzidos ao jovem Vargas e à sua carreira meteórica. É defensor de um Estado forte e é crítico do liberalismo econômico. No cap.3, ficamos vendo os detalhes dos anos de 1926 a 1930, em que Vargas foi deputado federal, minisiro da fazenda, candidato a presidente da república e finalmente líder de uma revolução. Nocap.4, cobrimos o período de 1930 a 1937. No cap.5, temos o Estado Novo e no cap.6, o Segundo Governo Vargas. Em todos os capítulos os ambientes político e econômico servem de referência e os principais tópicos da literatura são discutidos, com nova interpretação para vários deles. Assim, temos a questão das políticas monetária e fiscal nos anos triata, o desenvolvimentismo como legitimação do poder, o paraielismo com as idéias cepalinas etc.

O livro é especialmente adequado para a disciplina de Economia Brasileira dos cursos da área de Economia, tanto de graduação como de pós-graduação. Pode ser usado como complemento em disciplinas como Política e Programação Econômica, Desenvolvimento Econômico e Economia Industrial. Como o seu campo de ação é também a Ciência Política e a Sociologia, é útil para disciplinas daquelas áreas que cubram a história brasileira recente. 